\title{
EDIÇÃO DE GENOMAS PELO SISTEMA CRISPR-CAS E SUAS APLICAÇÕES: QUESTÕES ÉTICAS E JURÍDICAS NO CONTEXTO BRASILEIRO E OUTROS EXEMPLOS
}

\author{
CRISPR-CAS GENOME EDITING AND ITS APLICATIONS: ETHICAL AND \\ LEGAL ISSUES IN THE BRAZILIAN CONTEXT AND OTHER EXAMPLES
}

Diniz, M.M.P. ${ }^{1}$

Diniz, L.M.P. ${ }^{2}$

\begin{abstract}
RESUMO
Desde o desenvolvimento em 2012 da técnica de edição de genomas conhecida como CRISPR, sua aplicação se difundiu rapidamente, permitindo introduzir alterações planejadas no DNA de diversas linhagens celulares. A rápida difusão da técnica se deve a seu baixo custo, rapidez, simplicidade, possibilidade de uso em células germinativas e somáticas, e diversidade de aplicações em saúde, reprodução humana e melhoramento genético de plantas e animais. O uso da edição de genomas tem provado ser altamente eficaz como terapia potencial para doenças genéticas e não genéticas, e em modificação genética de embriões, entre outros diversos estudos. O tema tem, por isso, gerado grande interesse quanto aos aspectos éticos e legais do seu uso, que se mostram cada vez mais urgentes de serem discutidos pela bioética e pelo biodireito conforme os desdobramentos da técnica avançam. Algumas das principais polêmicas são as possíveis modificações das gerações futuras da espécie e assim impactos futuros por vezes imprevisíveis, além da possibilidade de eugenia na reprodução assistida. Como possibilidades reais, há indivíduos com deficiências genéticas que questionam se deve ou não ser permitido editar o genoma de seus embriões para não perpetuarem a característica; a possibilidade de alterar características meramente estéticas; e o caso concreto ocorrido na China, onde houve o nascimento de dois bebês teoricamente resistentes ao HIV por edição de seus genomas, além de vários estudos em andamento. Diante do exposto, este trabalho pretende contribuir levantando questões éticas e jurídicas a observar na edição de genomas, considerando o contexto brasileiro e exemplos internacionais.
\end{abstract}

Palavras-chave: Edição de Genomas, Biodireito, CRISPR

\begin{abstract}
Since the development in 2012 of the genome editing technique known as CRISPR, its application has spread rapidly, allowing for planned changes in the DNA of several cell lines. The rapid diffusion of the technique is due to its low cost, speed, simplicity, possibility of use in somatic and germline cells, and because of the diversity of applications in health, human reproduction and genetic improvement of plants and animals. The use of genome editing has proven to be highly effective as a potential therapy for genetic and non-genetic diseases, and in genetic modification of embryos, among many other studies. The subject has therefore generated great interest regarding the ethical and legal aspects of its use, which are becoming increasingly urgent to be discussed by bioethics and bio-rights as the technique unfolds. Some of the main controversies are the possible modifications of future generations of the species and thus sometimes unpredictable future impacts, besides the possibility of eugenics in
\end{abstract}

1 PhD/MSc em Ciências Biológicas - Biofísica pela Universidade Federal do Rio de Janeiro. ${ }^{+}$Graduanda em Direito pela Universidade Federal do Estado do Rio de Janeiro.

2 Graduanda em Saúde Coletiva pela Universidade Federal do Rio de Janeiro. 
assisted reproduction. As real possibilities, there are individuals with genetic disabilities who question whether or not to be allowed to edit the genome of their embryos so as not to perpetuate the trait; the possibility of altering merely aesthetic characteristics; and the concrete case in China, where two theoretically resistant HIV babies were born by editing their genomes, as well as several ongoing studies. Given the above, this paper aims to contribute by raising ethical and legal issues to be observed in genome editing, considering the Brazilian context and international examples.

Keywords: Genome Edition, Biolaw, CRISPR

\section{INTRODUÇÃO}

O presente trabalho visa fazer uma revisão dos marcos regulatórios existentes e das questões éticas e jurídicas relacionadas à Edição de Genomas pelo Sistema CRISPR-Cas.

O sistema de edição de genomas mencionado é um sistema natural de defesa bacteriano que em 2012 foi primeiramente descrito como potencial ferramenta de edição de DNA ${ }^{3}$. Tal sistema utiliza a propriedade de um "Conjunto de Repetições Palindrômicas Curtas Regularmente Espaçadas“(Clustered Regularly Interspaced Short Palindromic Repeats), entre as quais são inseridas sequências a serem reconhecidas como alvos de corte. Sempre convenientemente localizado perto dessas sequências de DNA está o gene que expressa uma enzima da família das Cas, geralmente a Cas9, que tem a capacidade de cortar precisamente o DNA nas sequências pretendidas. Entre suas principais vantagens entre as técnicas de alteração e manipulação de DNA de seres vivos, está sua simplicidade, rapidez e baixo custo. Além disso, a técnica é capaz de alterar características com uma precisão em nível nunca antes conseguida. Outra questão que a torna extremamente atrativa é o fato de poder ser utilizada tanto em células somáticas (diferenciadas - alterações não transmitidas à prole) quanto germinativas (gametas e embriões - portanto, transmitindo as caracteríticas à prole); e células de plantas, animais e humanos.

Alguns importantes avanços conseguidos até o presente utilizando a técnica de edição de genomas por CRISPR-Cas são, por exemplo ${ }^{4}$ :

- Tratamento da anemia falciforme;

- Plantações mais produtivas e resistentes à pragas e intempéries;

- Diminuição da população de mosquitos transmissores de doenças (como a malária) e

- Inúmeros outros trabalhos entre concluídos e em andamento.

3 JINEK, Martin et al. A programmable dual-RNA-guided DNA endonuclease in adaptive bacterial immunity. Science, v. 337, n. 6096, p. 816-821, 2012.

4 BARRANGOU, Rodolphe; DOUDNA, Jennifer A. Applications of CRISPR technologies in research and beyond. Nature biotechnology, v. 34, n. 9, p. 933, 2016. 
A técnica de CRISPR-Cas (também referida apenas como CRISPR) é simples e poderosa mas não perfeita, havendo uma pequena chance de inespecificidade de alvo e de alteração de outras características subsidiárias não previstas. Portanto, seu uso em humanos, principalmente em linhagens germinativas, é prematuro e deve levar em conta os riscos e incertezas. Além destes, outra preocupação são as possíveis destinações discutíveis da técnica, que resultem, por exemplo, em eugenia. Consequentemente, toda a comunidade científica e mesmo os políticos e legisladores andam preocupados com os limites da utilização da técnica. Questionamento similar já era prevista há muito pela arte, tendo em vista que, em 1997, o filme "Gattaca" já apresentava dilema de igual teor, como demonstrado pela sinopse do filme: "Preocupações sobre as tecnologias reprodutivas que facilitam a eugenia e as possíveis consequências de tais desenvolvimentos tecnológicos para a sociedade." 5

Assim, um consenso majoritário entre os cientistas é o de evitar a edição do genoma de células germinativas, com raras exceções permitidas a estudos como por exemplo no Reino Unido, apenas até os primeiros estágios do desenvolvimento, porém com os embriões descartados logo após ${ }^{6}$.

Tal preocupação veio a mostrar, em 2018, a sua justificativa: um cientista chinês anunciou ao mundo, em novembro do referido ano, o nascimento de duas gêmeas chinesas resistentes ao HIV por edição de seus genomas ${ }^{7}$, como veremos em mais detalhes adiante.

Trabalhos na área de bioética já indicam que deve-se sopesar quando o princípio da precaução deveria influenciar a tomada de decisões na permissão de pesquisas com o uso da técnica de CRISPR ${ }^{8}$. De uma maneira geral, deve-se dar um maior peso a evitar ameaças às futuras gerações do que conseguir benefícios mais imediatos. Interessante notar que em algumas regulações genéricas internacionais no tema de patrimônio genético consultadas, como a Declaração Universal do Genoma Humano e dos Direitos Humanos ${ }^{9}$ de 1997, e mesmo a própria Constituição brasileira de 1988 (em seu artigo 225) ${ }^{10}$, a principal preocupação expressa está em preservar a integridade do patrimônio genético (não só do homem mas de todas as

5 GATTACA. In: WIKIPÉDIA, a enciclopédia livre. Flórida: Wikimedia Foundation, 2019. Disponível em: <https://pt.wikipedia.org/w/index.php?title=Gattaca\&oldid=55600624>. Acesso em: 28 jun. 2019.

6 CALLAWAY, Ewen. UK scientists gain licence to edit genes in human embryos. Nature News, v. 530, n. 7588, p. 18, 2016.

7 CYRANOSKI, David; LEDFORD, Heidi. Genome-edited baby claim provokes international outcry. Nature, v. 563, n. 7733, p. 607-608, 2018.

8 KOPLIN, Julian J.; GYNGELL, Christopher; SAVULESCU, Julian. Germline gene editing and the precautionary principle. Bioethics, 2019.

9 DECLARAÇÃO Universal sobre o Genoma Humano e os Direitos Humanos. [S.1.: s.n.], 1997. Disponível em: http://unesdoc.unesco.org/images/0012/001229/122990por.pdf. Acesso em: 05 jul. 2019.

10 BRASIL. Constituição da República Federativa do Brasil, promulgada em 05 de outubro de 1988. Brasília, DF: Senado Federal, 1988. 
espécies) para as gerações futuras. Dessa maneira, discutir as implicações morais, éticas e legais do uso da edição de genomas pela técnica CRISPR-Cas, que já vem sendo amplamente utilizada no Brasil, com resultados práticos já visíveis, por exemplo, no campo da agricultura, é necessidade imperativa nos dias atuais.

\section{OBJETIVO}

O objeto da pesquisa, tal como anunciado, é elencar questões éticas e jurídicas envolvidas com o uso da técnica de edição de genomas no contexto brasileiro, utilizando ainda exemplos internacionais para nortear a discussão.

Para tanto, será revisto o que há de legislação internacional e pátria regulando a questão, quais os conceitos importantes relacionados ao tema e em que ponto está a discussão no âmbito nacional.

\section{METODOLOGIA}

A metodologia utilizada se traduz na pesquisa e análise de alguns dos principais dispositivos normativos internacionais e brasileiros regulando o uso da edição de genomas e manipulação da informação genética vigentes, com a subsequente análise e apontamento ressaltando pontos controversos à luz das questões éticas concernentes ao tema e que devem ser observadas pelos postulantes ao uso da CRISPR em pesquisa e mesmo aos legisladores que se prestarem a regular o tema.

\section{LEGISLAÇÃO REGULATÓRIA ASSOCIADA À EDIÇÃO DE GENOMAS}

\section{CONSIDERAÇÕES INICIAIS EM REGULAÇÃO DO TEMA}

Antes de endereçarmos propriamente os conteúdos normativos que se dispõem a disciplinar e/ou nortear a utilização da informação e da diversidade genética dos seres vivos, e mais especificamente, a manipulação de DNA por técnicas como a edição de genomas e outras afins, há que se ressaltar que muito da normatização que se relacione de alguma maneira ao uso da técnica de edição de genomas utilizando o sistema CRISPR foi na verdade criada direcionada a regular modificações em embriões humanos e plantações melhoradas geneticamente, e por tal motivo, muito da normatividade a ser considerada neste item trata destes temas em particular. 
Deve-se considerar também que outra questão peculiar é que o uso de CRISPR e técnicas afins expande as fronteiras do que é considerado engenharia genética; e portanto, os regimes regulatórios não costumam cobrir seus produtos, daí a dificuldade de encontrar marcos regulatórios diretamente relacionados à matéria. ${ }^{11}$

Outra questão que dificulta a regulação da matéria é a terminologia um tanto confusa (principalmente para os indivíduos sem uma formação bastante aprofundada na área), e às vezes sobreposta, ou mesmo a utilização errônea de alguns dos termos como sinônimos, como por exemplo, no caso dos termos "organismos geneticamente modificados" (ou OGMs), "transgênicos" e/ou "editados". Por esse motivo, muitos dos estudiosos da área aduzem que o foco para denominação não deveria ser no método, mas sim na extensão e inovação da alteração no DNA do organismo em questão. ${ }^{12}$

Por fim, outra questão mais geral a ser pontuada, e que vem sendo amplamente defendida por especialistas na área, é que quaisquer novas variedades genéticas obtidas pela edição de genomas e técnicas afins devem ser testadas quanto a possíveis novas características criadas (intencionalmente ou não) através de estudos de comparação de proteínas em larga escala em relação ao espécime padrão; ou, trocando em miúdos: uma análise minuciosa de toda a alteração no padrão de expressão de genes e seus produtos deve estabelecer possíveis efeitos indesejados e ou danosos seja às espécies nativas, ao meio ambiente ou à saúde humana e de outros seres vivos. $^{13}$

\section{PRINCIPAIS MARCOS REGULATÓRIOS INTERNACIONAIS}

Como bem ressaltado por Norberto Bobbio, os direitos humanos são direitos históricos, gerados gradualmente em circunstâncias de luta em defesa de sua positivação, por mais fundamentais que sejam. ${ }^{14} \mathrm{O}$ Biodireito seria, dessa maneira, a quarta dimensão dos Direitos Humanos ${ }^{15}$, surgida frente a toda revolução biotecnológica a que o mundo vem testemunhando, principalmente desde o século $\mathrm{XX}$, e vem sendo positivado em documentos internacionais direta e indiretamente desde a metade do referido século. Como marcos fundantes destacamos,

11 VOGEL, Kathleen M. Crispr goes global: a snapshot of rules, policies, and attitudes. Bull At Sci, 2018.

12 RICROCH, Agnès. Global developments of genome editing in agriculture. In: Transgenic research. Springer International Publishing, 2019. p. 45-52..

13 HWANG, Woong Y. et al. Efficient genome editing in zebrafish using a CRISPR-Cas system. Nature biotechnology, v. 31, n. 3, p. 227, 2013.

14 BOBBIO, Norberto. Era dos direitos. Elsevier Brasil, 2004.

15 BONAVIDES, Paulo. Curso de Direito Constitucional. 26 ${ }^{\text {a }}$. São Paulo: Malheiros, 2011. 
inicialmente, para o Código de Nuremberg, de $1947^{16}$, e, por fim, a Declaração Universal de Direitos do Homem, de $1948^{17}$, emitidos no contexto pós-guerra e dando início ao reconhecimento de direitos humanos relacionados à vida. ${ }^{18}$ Mas em que pese a inauguração da positivação do Biodireito em âmbito internacional por esses e outros diplomas, apenas muito mais tarde começou a tentativa mais direta de regular os direitos relacionados à informação genética e à sua manipulação, como veremos a seguir.

\section{DECLARAÇÃO DE VALÊNCIA SOBRE ÉTICA E O PROJETO GENOMA}

Era o fim da década de 80, e deu-se início ao Projeto Genoma Humano, em 1990, consórcio científico destinado a sequenciar e decifrar todo o código da eucromatina dos seres humanos. O sequenciamento do genoma humano prometia trazer benefícios para muitas áreas, da medicina molecular à evolução humana; poderia nos ajudar a entender doenças, incluindo: a possibilidade de direcionar o tratamento apropriado de vírus específicos; a identificação de mutações ligadas a diferentes formas de câncer; o desenho de fármacos e previsão mais precisa de seus efeitos; o avanço em ciências aplicadas forenses; e uma série de outros possíveis avanços. Outro benefício proposto é o desenvolvimento comercial de pesquisas genômicas relacionadas a produtos baseados em DNA, uma indústria multibilionária. ${ }^{19}$

Um aspecto particular do Projeto Genoma Humano, desde seu princípio, é que este procurou, juntamente com a identificação de todos os genes do genoma humano, abordar também os aspectos éticos, legais e sociais envolvidos. Para isso, um braço do Programa, relacionado às Implicações Éticas, Legais e Sociais (ELSI) foi fundado, tendo cerca de cinco por cento do orçamento anual alocado apenas para abordar o ELSI decorrente do projeto. ${ }^{20}$

E não só seus membros, mas toda a comunidade internacional questionava preocupada as possíveis implicações de decifrar o código genético humano, e possíveis desdobramentos indesejáveis para o futuro da espécie humana e de nosso patrimônio genético. ${ }^{21}$

16 CODE, Nuremberg. The Nuremberg Code. Trials of war criminals before the Nuremberg military tribunals under control council law, v. 10, p. 181-182, 1949.

17 ASSEMBLY, UN General. Universal declaration of human rights, 10 December 1948, 217 A (III). 1948.

18 ROCHA, Renata da. Fundamentos do Biodireito. 1. ed. São Paulo: Juspodivm, 2018.

19 GREEN, Eric D.; WATSON, James D.; COLLINS, Francis S. Human Genome Project: Twenty-five years of big biology. Nature News, v. 526, n. 7571, p. 29, 2015..

20 THOMSON, Elizabeth J.; BOYER, Joy T.; MESLIN, Eric Mark. The ethical, legal, and social implications research program at the National Human Genome Research Institute. Kennedy Institute of Ethics Journal, v. 7, n. 3, p. 291-298, 1997.

21 KEVLES, Daniel J.; HOOD, Leroy E. (Ed.). The code of codes: Scientific and social issues in the human genome project. Harvard University Press, 1992. 
Nesse contexto de preocupação com os direitos relacionados à informação genética e à sua utilização e alteração, é que surge em 1990, a Declaração de Valência sobre Ética, a qual se manifestou favorável à terapia gênica em células somáticas, declarada como jurídica e eticamente aceitável por não comprometer o patrimônio genético de populações futuras e por oferecer uma melhor qualidade de vida aos submetidos ao tratamento. No entanto, no mesmo diploma normativo, optou-se por apontar o inexistente consenso ético quanto à mesma matéria em células germinativas. ${ }^{22}$

\section{DECLARAÇÃO DE BILBAO SOBRE O DIREITO ANTE O PROJETO GENOMA HUMANO}

Em 1993, outra reflexão dos riscos do Projeto Genoma Humano dá origem a um documento normativo internacional, a Declaração de Bilbao sobre o Direito ante o Projeto Genoma Humano (mais conhecida apenas como Declaração de Bilbao), fruto da reunião de diversos juristas, filósofos e cientistas. A Declaração de Bilbao alerta para possíveis práticas de eugenia, já observadas em sua essência nos regimes nazistas, e, portanto, recomenda princípios de pesquisa e utilização das informações genéticas que se pautem pelo respeito à dignidade humana. A Declaração traz ainda a marcante idéia de que a diversidade genética é atributo dos seres humanos livres, não cabendo espaço para discriminação neste âmbito. ${ }^{23}$

\section{DECLARAÇÃO UNIVERSAL DO GENOMA HUMANO E DOS DIREITOS HUMANOS}

Em 1997, é emitida a Declaração Universal do Genoma Humano e dos Direitos Humanos ${ }^{24}$, inovadora em termos de direito internacional quando passa a reconhecer as gerações presentes e futuras da humanidade como titulares de direitos, como expresso em seu artigo $1^{\mathrm{o}}$ :

\footnotetext{
"O genoma humano subjaz à unidade fundamental de todos os membros da família humana e também ao reconhecimento de sua dignidade e diversidade inerentes. Num sentido simbólico, é a herança da humanidade."
}

Ou seja, para este diploma, o Genoma Humano e informação nele contida é herança comum de toda a humanidade, que seria sua titular de direitos, atuais e futuros. Aduz ainda que

22 ROCHA, Renata da. $\mathbf{O}$ direito à vida e a pesquisa com células tronco: limites éticos e jurídicos. Rio de Janeiro: Campus jurídicos, 2008.

23 SANTOS, Maria Celeste Cordeiro Leite et al. Biodireito: ciência da vida, os novos desafios. São Paulo: Revista dos Tribunais, p. 214-245, 2001.

24 UNESCO INTERNATIONAL BIOETHICS COMMITTEE et al. Universal declaration on the human genome and human rights. 1997. 
cada país deve, de acordo com seus próprios valores, tutelar seu patrimônio genético do momento da concepção. Há que se observar ainda o disposto em seu artigo $10^{\circ}$ :

"Nenhuma pesquisa ou aplicação de pesquisa relativa ao genoma humano, em especial nos campos da biologia, genética e medicina, deve prevalecer sobre o respeito aos direitos humanos, às liberdades fundamentais e à dignidade humana dos indivíduos ou, quando for o caso, de grupos de pessoas."

\section{CONVENÇÃO SOBRE OS DIREITOS DO HOMEM E DA BIOMEDICINA}

A referida convenção de $1997^{25}$, bem como suas prévias recomendações 1046 e $1100^{26}$, definiram, em linhas gerais, mais proteções para os embriões face às pesquisas, com ressalvas para os casos onde o beneficiado seja o próprio embrião.

\section{DECLARAÇÃO IBERO-LATINO-AMERICANA SOBRE ÉTICA E GENÉTICA}

Em 1996, a Declaração Ibero-latino-americana sobre Ética e Genética (também chamada de Declaração de Manzanillo), ratificou os princípios expressos pela Declaração Universal do Genoma Humano e dos Direitos Humanos (como denota a redação de seu artigo segundo reproduzido a seguir) e, após revisão em 1998, pela Convenção sobre os Direitos do Homem e da Biomedicina ${ }^{27}$.

\footnotetext{
"SEGUNDO: A reflexão sobre as diversas implicâncias do desenvolvimento científico e tecnológico no campo da genética humana deve ser feita levando em consideração:

a) o respeito à dignidade, à identidade e à integridade humanas e aos direitos humanos reafirmados nos documentos jurídicos internacionais;

b) que o genoma humano constitui parte do patrimônio comum da humanidade como uma realidade e não como uma expressão meramente simbólica;"
}

CARTA DE DIREITOS FUNDAMENTAIS DA UNIÃO EUROPÉIA E TRATADO DE LISBOA

25 COUNCIL, OF EUROPE. Convention for the Protection of Human Rights and Dignity of the Human Being with regard to the Application of Biology and Medicine: Convention on Human Rights and Biomedicine. Oviedo: COE, 1997.

26 PARLIAMENTARY Assembly of the Council of Europe. On the use of human embryos and foetuses for diagnostic, therapeutic, scientific, industrial and commercial purposes. Recommendations 1046 and 1100. Strasbourg: Council of Europe, 1986.

27 DIEDRICH, Gislayne Fátima. Genoma Humano: direito internacional e legislação brasileira. Biodireito, ciência da vida, os novos desafios.(org.) Maria Celeste Cordeiro Leite Santos-São Paulo: RT, 2001. 
Em 2000, é aprovada a Carta de Direitos Fundamentais da União Européia ${ }^{28}$ (a qual em 2007 adquire força jurídica vinculativa com a assinatura do Tratado de $\mathrm{Lisboa}^{29}$ ). A Carta proibe práticas de eugenia para selecionar pessoas, a transformação do corpo humano em fonte de lucro e a clonagem humana reprodutiva, conforme redação de seu artigo $3^{\circ}$ :

“Artigo 3.o Direito à integridade do ser humano

1. Todas as pessoas têm direito ao respeito pela sua integridade física e mental.

2. No domínio da medicina e da biologia, devem ser respeitados, designadamente: o consentimento livre e esclarecido da pessoa, nos termos da lei, a proibição das práticas eugênicas, nomeadamente das que têm por finalidade a selecção das pessoas, a proibição de transformar o corpo humano ou as suas partes, enquanto tais, numa fonte de lucro, a proibição da clonagem reprodutiva dos seres humanos."

\section{POSITIVAÇÃO CONSTITUCIONAL DE PROTEÇÕES DO PATRIMÔNIO GENÉTICO FRENTE ÀS PESQUISAS}

Tais proteções passam a ser positivadas em algumas constituições. Como exemplo, podemos citar as Constituições de Suiça ${ }^{30}$ (positivando a matéria tanto em âmbito humano como não humano em 1992) e Portugal ${ }^{31}$ (1997). Vejamos primeiro em particular o que preconizam os artigos 119 (que versa sobre medicina reprodutiva e tecnologia genética envolvendo seres humanos) e 120 (que versa sobre tecnologia genética não humana) da pioneira Constituição da Confederação Suiça:

“Art. 119 Medicina reprodutiva e tecnologia genética envolvendo seres humanos

1. Seres humanos devem ser protegidos contra uso indevido de medicina reprodutiva e tecnologia genética.

2. A Confederação legislará sobre o uso de material genético e reprodutivo humano. Ao fazê-lo, assegurará a protecção da dignidade humana, a privacidade e a família e respeitará, em particular, os seguintes princípios:

a. Todas as formas de clonagem e interferência com o material genético de células reprodutoras humanas e embriões são ilegais.

b. Materiais reprodutivos e genéticos não humanos não podem ser introduzidos nem combinados com material reprodutivo humano.

c. Os procedimentos para reprodução medicamente assistida só podem ser usados se a infertilidade ou o risco de transmissão de uma doença grave não puder ser superada, mas não para conceber uma criança com características específicas ou para pesquisas posteriores; a fertilização de óvulos humanos fora do corpo de uma mulher só é permitida nas condições estabelecidas pela lei; não mais óvulos humanos podem ser desenvolvidos em embriões fora do corpo de uma mulher do que o necessário para a reprodução assistida por médicos.

d. A doação de embriões e todas as formas de maternidade substituta são ilegais.

28 SILVEIRA, Canotilho et al. Carta dos Direitos Fundamentais da União Europeia Comentada. Leya, 2014.

29 EUROPEA, Unión. Tratado de Lisboa. Diario Oficial de la Unión Europea, v. 100, 2007.

30 SWISS CONFEDERATION. Federal Constitution of the Swiss Confederation. Disponível em: https://www.admin.ch/opc/en/classified-compilation/19995395/index.html. Acesso em: 25 ago. 2019.

31 MIRANDA, Jorge; MEDEIROS, Rui; FERREIRA, Eduardo Paz. Constituição portuguesa anotada. Coimbra: Coimbra Editora, 2005. 
e. É proibido o comércio de material de reprodução humana e de produtos obtidos a partir de embriões.

f. O material genético de uma pessoa pode ser analisado, registrado ou tornado público somente com o consentimento da pessoa envolvida ou se a lei assim o permitir.

g. Toda pessoa deve ter acesso aos dados relacionados à sua ascendência."

"Art. 120 Tecnologia genética não humana

1. Os seres humanos e seu meio ambiente devem ser protegidos contra o uso indevido da tecnologia genética.

2. A Confederação deve legislar sobre o uso de material genético e reprodutivo de animais, plantas e outros organismos. Ao fazê-lo, terá em conta a dignidade dos seres vivos, bem como a segurança dos seres humanos, dos animais e do ambiente, e protegerá a diversidade genética das espécies animais e vegetais."

Agora, passemos ao artigo 26 item 3 da Constituição Portuguesa:

“Artigo 26. ${ }^{\circ}$ Outros direitos pessoais

(...)

3. A lei garantirá a dignidade pessoal e a identidade genética do ser humano, nomeadamente na criação, desenvolvimento e utilização das tecnologias e na experimentação científica."

É possível depreender, destes dispositivos constitucionais, uma preocupação patente com a manipulação de informações genéticas dos seres vivos, que agora tende a ser imitada por outras nações frente às inovações na alteração de DNA por técnicas tão revolucionárias quanto a edição de DNA por CRISPR.

\section{LEGISLAÇÃO BRASILEIRA EM REGULAÇÃO DE MATÉRIAS RELACIONADAS À EDIÇÃO DE GENOMAS}

A verdade é que, se há muito pouco ou quase nada em termos de normativos internacionais regulando as pesquisas com manipulação de informações genéticas dos seres vivos, no Brasil estamos na mesma situação regulatória. A primeira regulamentação a fazer menção expressa à edição de genomas foi a Resolução nº 16/2018 do CTNBio editada há apenas um ano (escrutinada em mais detalhes em itens subsequentes), e graças a um Projeto de Decreto Legislativo de Sustação tramitando na Câmara dos Deputados, é possível que mesmo tal regulamentação deixe de vigorar. Neste item, são apresentadas os principais normativos nacionais de alguma forma associados à matéria, e que culminaram na Resolução supramencionada.

POSITIVAÇÃO CONSTITUCIONAL DE PROTEÇÕES AO PATRIMÔNIO GENÉTICO NO BRASIL 
A temática da pesquisa científica relacionada a ciências da vida é regulada inicialmente pelo caput (direito à vida) e pelo inciso IX (liberdade de pesquisa científica) do $\operatorname{artigo} 5^{\circ}$ da $\mathrm{CRFB}^{32}$, que por sua vez foi a primeira Carta Magna a tratar deliberadamente da questão ambiental e do patrimônio genético. O núcleo desta matéria é encontrado em seu artigo 225, o qual preconiza:

\footnotetext{
"Art. 225. Todos têm direito ao meio ambiente ecologicamente equilibrado,bem de uso comum do povo e essencial à sadia qualidade de vida, impondo-se ao Poder Público e à coletividade o dever de defendê-lo e preservá- lo para as presentes e futuras gerações.

$\S 1^{\circ}$ - Para assegurar a efetividade desse direito, incumbe ao Poder Público:

I - preservar e restaurar os processos ecológicos essenciais e prover o manejo ecológico das espécies e ecossistemas;

II - preservar a diversidade e a integridade do Patrimônio Genético do País e fiscalizar as entidades dedicadas à pesquisa e manipulação de material genético;

III - definir, em todas as unidades da Federação, espaços territoriais e seus componentes a serem especialmente protegidos, sendo a alteração e a supressão permitidas somente através de lei, vedada qualquer utilização que comprometa a integridade dos atributos que justifiquem sua proteção;

IV - exigir, na forma da lei, para instalação de obra ou atividade potencialmente causadora de significativa degradação do meio ambiente, estudo prévio de impacto ambiental, a que se dará publicidade;

V - controlar a produção, a comercialização e o emprego de técnicas, métodos e substâncias que comportem risco para a vida, a qualidade de vida e o meio ambiente; VI - promover a educação ambiental em todos os níveis de ensino e a conscientização pública para a preservação do meio ambiente;

VII - proteger a fauna e a flora, vedadas, na forma da lei, as práticas que coloquem em risco sua função ecológica, provoquem a extinção de espécies ou submetam os animais à crueldade."
}

Como depreendido do normativo constitucional acima, o meio ambiente é um bem de uso comum, juridicamente classificado como um direito difuso. E considerando que o Patrimônio Genético está incluso na regulação sobre o meio ambiente, qualquer alteração no mesmo, por meio de manipulação de todo e qualquer material, deve seguir as orientações legais sobre os direitos difusos e do meio ambiente. Dentre os princípios do Direito Ambiental que devem ser observados a fim de preservar o Patrimônio Genético brasileiro, temos o Princípio da Prevenção, que pode ser depreendido do inciso VII do dispositivo supracitado, segundo o qual se sabe que nem todo dano causado ao meio ambiente poderá ser reparado ou compensado, como por exemplo, a extinção de uma espécie. Dessa forma, é de extrema importância investir na prevenção dos danos.

Embora a Carta Magna apresentasse a positivação constitucional da preocupação com o patrimônio genético de todas as espécies, esta ainda carecia de regulamentação posterior, que se iniciou com os dispositivos infraconstitucionais elencados a seguir.

32 BRASIL. Constituição da República Federativa do Brasil, promulgada em 05 de outubro de 1988. Brasília, DF: Senado Federal, 1988. 
POSITIVAÇÃO INFRACONSTITUCIONAL DE PROTEÇÕES AO PATRIMÔNIO GENÉTICO NO BRASIL

Antes e depois da promulgação da Constituição Federal de 1988, algumas leis foram criadas acerca da proteção do meio ambiente e da Diversidade Genética. As leis pátrias não vedam modificações do Patrimônio Genético brasileiro, mas tornam obrigação do Estado fiscalizar as pesquisas nessa área, a fim de preservar nossa biodiversidade. Eis as principais:

\section{LEI N ${ }^{o}$ 6.938/1981 (POLÍTICA NACIONAL DO MEIO AMBIENTE) $)^{33}$}

Esta lei dispõe sobre a Política Nacional do Meio Ambiente e dá outras providências, é anterior à Constituição Federal e também serve de base para as legislações posteriores.

\section{MEDIDA PROVISÓRIA No2.186-16/200134}

Estabelece diretrizes para o uso desse Patrimônio Genético, regulamentando não apenas o acesso aos recursos genéticos, mas também englobando as formas de repartição dos benefícios vindouros dos produtos gerados a partir do uso de conhecimentos tradicionais associados explorados, além de definir e criar as instituições responsáveis pela aplicação da MP, como o Conselho de Gestão do Patrimônio Genético (CGEN). No entanto, na prática, porém, essa lei criou barreiras para a Pesquisa \& Desenvolvimento (P\&D), trouxe obstáculos à inovação e as patentes, interferiu nas colaborações internacionais e não conseguiu fazer a repartição de benefícios de forma satisfatória.

LEI 8974/1995 (PRIMEIRA LEI DE BIOSSEGURANÇA OU DA ENGENHARIA GENÉTICA) ${ }^{35}$

Em 1995 é editada a Lei 8974/1995 (primeira Lei de Biossegurança ou da Engenharia Genética). Esta se dispõe a regular toda a biotecnologia, inclusive os OGMs. No entanto, não autoriza pesquisa com embriões humanos, e cria a Comissão Técnica Nacional de

BRASIL. LEI No 6.938/1981. Dispõe sobre a Política Nacional do Meio Ambiente. 1981.

34 BRASIL. MEDIDA PROVISÓRIA N².186-16/2001. Dispõe sobre dispõe sobre o acesso ao patrimônio genético. 2001.

35 BRASIL. LEI 8974/1995. Dispõe sobre as normas para o uso das técnicas de engenharia genética e liberação no meio ambiente de organismos geneticamente modificados. 1995. 
Biossegurança (CTNBio), responsável por emitir pareceres em segurança, liberação, cultivo e uso de OGMs na alimentação.

LEI 11.105/2005 (ATUALIZA A LEI DE BIOSSEGURANÇA) ${ }^{36}$

A Lei 11.105/2005, que surge para atualizar a Lei de Biossegurança, e se constitui num marco jurídico da Biotecnologia, e se dispõe a também regulamentar os incisos II, IV e V do $\S$ $1^{\circ}$ do art. 225 da Constituição Federal, estabelecer normas de segurança e mecanismos de fiscalização de atividades que envolvam organismos geneticamente modificados - OGM e seus derivados, cria o Conselho Nacional de Biossegurança-CNBS, reestrutura a Comissão Técnica Nacional de Biossegurança - CTNBio, e dispõe sobre a Política Nacional de Biossegurança PNB. Reproduzimos abaixo alguns artigos da referida lei:

Art. $1^{\circ}$ Esta Lei estabelece normas de segurança e mecanismos de fiscalização sobre a construção, o cultivo, a produção, a manipulação, o transporte, a transferência, a importação, a exportação, o armazenamento, a pesquisa, a comercialização, o consumo, a liberação no meio ambiente e o descarte de organismos geneticamente modificados - OGM e seus derivados, tendo como diretrizes o estímulo ao avanço científico na área de biossegurança e biotecnologia, a proteção à vida e à saúde humana, animal e vegetal, e a observância do princípio da precaução para a proteção do meio ambiente.

$\S 1^{\circ}$ Para os fins desta Lei, considera-se atividade de pesquisa a realizada em laboratório, regime de contenção ou campo, como parte do processo de obtenção de OGM e seus derivados ou de avaliação da biossegurança de OGM e seus derivados, o que engloba, no âmbito experimental, a construção, o cultivo, a manipulação, o transporte, a transferência, a importação, a exportação, o armazenamento, a liberação no meio ambiente e o descarte de OGM e seus derivados.

$\S 2^{\circ}$ Para os fins desta Lei, considera-se atividade de uso comercial de OGM e seus derivados a que não se enquadra como atividade de pesquisa, e que trata do cultivo, da produção, da manipulação, do transporte, da transferência, da comercialização, da importação, da exportação, do armazenamento, do consumo, da liberação e do descarte de OGM e seus derivados para fins comerciais.

Art. $2^{\circ}$ As atividades e projetos que envolvam OGM e seus derivados, relacionados ao ensino com manipulação de organismos vivos, à pesquisa científica, ao desenvolvimento tecnológico e à produção industrial ficam restritos ao âmbito de entidades de direito público ou privado, que serão responsáveis pela obediência aos preceitos desta Lei e de sua regulamentação, bem como pelas eventuais conseqüências ou efeitos advindos de seu descumprimento.

$\S 1^{\circ}$ Para os fins desta Lei, consideram-se atividades e projetos no âmbito de entidade os conduzidos em instalações próprias ou sob a responsabilidade administrativa, técnica ou científica da entidade.

$\S 2^{\circ}$ As atividades e projetos de que trata este artigo são vedados a pessoas físicas em atuação autônoma e independente, ainda que mantenham vínculo empregatício ou qualquer outro com pessoas jurídicas.

$\S 3^{\circ}$ Os interessados em realizar atividade prevista nesta Lei deverão requerer autorização à Comissão Técnica Nacional de Biossegurança - CTNBio, que se manifestará no prazo fixado em regulamento.

36 BRASIL. LEI 11.105/2005. Dispõe sobre as normas de segurança e mecanismos de fiscalização de atividades que envolvam organismos geneticamente modificados. 2005. 
$\S 4^{\circ}$ As organizações públicas e privadas, nacionais, estrangeiras ou internacionais, financiadoras ou patrocinadoras de atividades ou de projetos referidos no caput deste artigo devem exigir a apresentação de Certificado de Qualidade em Biossegurança, emitido pela CTNBio, sob pena de se tornarem co-responsáveis pelos eventuais efeitos decorrentes do descumprimento desta Lei ou de sua regulamentação.Art. $3^{\circ}$ Para os efeitos desta Lei, considera-se:

I - organismo: toda entidade biológica capaz de reproduzir ou transferir material genético, inclusive vírus e outras classes que venham a ser conhecidas;

II - ácido desoxirribonucléico - ADN, ácido ribonucléico - ARN: material genético que contém informações determinantes dos caracteres hereditários transmissíveis à descendência;

III - moléculas de ADN/ARN recombinante: as moléculas manipuladas fora das células vivas mediante a modificação de segmentos de ADN/ARN natural ou sintético e que possam multiplicar-se em uma célula viva, ou ainda as moléculas de ADN/ARN resultantes dessa multiplicação; consideram-se também os segmentos de ADN/ARN sintéticos equivalentes aos de ADN/ARN natural;

IV - engenharia genética: atividade de produção e manipulação de moléculas de ADN/ARN recombinante;

$\mathrm{V}$ - organismo geneticamente modificado - OGM: organismo cujo material genético - ADN/ARN tenha sido modificado por qualquer técnica de engenharia genética;

VI - derivado de OGM: produto obtido de OGM e que não possua capacidade autônoma de replicação ou que não contenha forma viável de OGM;

VII - célula germinal humana: célula-mãe responsável pela formação de gametas presentes nas glândulas sexuais femininas e masculinas e suas descendentes diretas em qualquer grau de ploidia;

VIII - clonagem: processo de reprodução assexuada, produzida artificialmente, baseada em um único patrimônio genético, com ou sem utilização de técnicas de engenharia genética;

IX - clonagem para fins reprodutivos: clonagem com a finalidade de obtenção de um indivíduo;

$\mathrm{X}$ - clonagem terapêutica: clonagem com a finalidade de produção de células-tronco embrionárias para utilização terapêutica;

XI - células-tronco embrionárias: células de embrião que apresentam a capacidade de se transformar em células de qualquer tecido de um organismo.

$\S 1^{\circ}$ Não se inclui na categoria de OGM o resultante de técnicas que impliquem a introdução direta, num organismo, de material hereditário, desde que não envolvam a utilização de moléculas de ADN/ARN recombinante ou OGM, inclusive fecundação in vitro, conjugação, transdução, transformação, indução poliplóide e qualquer outro processo natural.

$\S 2^{\circ}$ Não se inclui na categoria de derivado de OGM a substância pura, quimicamente definida, obtida por meio de processos biológicos e que não contenha OGM, proteína heteróloga ou ADN recombinante.

Art. $4^{\circ}$ Esta Lei não se aplica quando a modificação genética for obtida por meio das seguintes técnicas, desde que não impliquem a utilização de OGM como receptor ou doador:

I - mutagênese;

II - formação e utilização de células somáticas de hibridoma animal;

III - fusão celular, inclusive a de protoplasma, de células vegetais, que possa ser produzida mediante métodos tradicionais de cultivo;

IV - autoclonagem de organismos não-patogênicos que se processe de maneira natural.

Art. $5^{\circ}$ É permitida, para fins de pesquisa e terapia, a utilização de células-tronco embrionárias obtidas de embriões humanos produzidos por fertilização in vitro e não utilizados no respectivo procedimento, atendidas as seguintes condições:

I - sejam embriões inviáveis; ou

II - sejam embriões congelados há 3 (três) anos ou mais, na data da publicação desta Lei, ou que, já congelados na data da publicação desta Lei, depois de completarem 3 (três) anos, contados a partir da data de congelamento.

$\S 1^{\circ}$ Em qualquer caso, é necessário o consentimento dos genitores. 
$\S 2^{\circ}$ Instituições de pesquisa e serviços de saúde que realizem pesquisa ou terapia com células-tronco embrionárias humanas deverão submeter seus projetos à apreciação e aprovação dos respectivos comitês de ética em pesquisa.

$\S 3^{\circ}$ É vedada a comercialização do material biológico a que se refere este artigo e sua prática implica o crime tipificado no art. 15 da Lei $n^{\circ} 9.434$, de 4 de fevereiro de 1997.

Art. $6^{\circ}$ Fica proibido:

I - implementação de projeto relativo a OGM sem a manutenção de registro de seu acompanhamento individual;

II - engenharia genética em organismo vivo ou o manejo in vitro de ADN/ARN natural ou recombinante, realizado em desacordo com as normas previstas nesta Lei; III - engenharia genética em célula germinal humana, zigoto humano e embrião humano;

IV - clonagem humana;

$\mathrm{V}$ - destruição ou descarte no meio ambiente de OGM e seus derivados em desacordo com as normas estabelecidas pela CTNBio, pelos órgãos e entidades de registro e fiscalização, referidos no art. 16 desta Lei, e as constantes desta Lei e de sua regulamentação;

VI - liberação no meio ambiente de OGM ou seus derivados, no âmbito de atividades de pesquisa, sem a decisão técnica favorável da CTNBio e, nos casos de liberação comercial, sem o parecer técnico favorável da CTNBio, ou sem o licenciamento do órgão ou entidade ambiental responsável, quando a CTNBio considerar a atividade como potencialmente causadora de degradação ambiental, ou sem a aprovação do Conselho Nacional de Biossegurança - CNBS, quando o processo tenha sido por ele avocado, na forma desta Lei e de sua regulamentação;

VII - a utilização, a comercialização, o registro, o patenteamento e o licenciamento de tecnologias genéticas de restrição do uso.

Parágrafo único. Para os efeitos desta Lei, entende-se por tecnologias genéticas de restrição do uso qualquer processo de intervenção humana para geração ou multiplicação de plantas geneticamente modificadas para produzir estruturas reprodutivas estéreis, bem como qualquer forma de manipulação genética que vise à ativação ou desativação de genes relacionados à fertilidade das plantas por indutores químicos externos.

Art. $7^{\circ}$ São obrigatórias:

I - a investigação de acidentes ocorridos no curso de pesquisas e projetos na área de engenharia genética e o envio de relatório respectivo à autoridade competente no prazo máximo de 5 (cinco) dias a contar da data do evento;

II - a notificação imediata à CTNBio e às autoridades da saúde pública, da defesa agropecuária e do meio ambiente sobre acidente que possa provocar a disseminação de OGM e seus derivados;

III - a adoção de meios necessários para plenamente informar à CTNBio, às autoridades da saúde pública, do meio ambiente, da defesa agropecuária, à coletividade e aos demais empregados da instituição ou empresa sobre os riscos a que possam estar submetidos, bem como os procedimentos a serem tomados no caso de acidentes com OGM.

Dos dispositivos reproduzidos, podemos denotar algumas coisas: as definições da lei para os organismos com alterações genéticas não necessariamente conseguiriam alcançar todas as possibilidades do presente (art. $3^{\circ}$ ); além disso, a lei se fundamenta, como já apontado, no princípio da precaução $\left(\operatorname{art.~} 1^{\circ}\right.$ ); e por fim, o normativo inova ao autorizar alguns usos restritos de embriões, porém proíbe a clonagem e a engenharia genética germinativa (arts. $5^{\circ}$ e $6^{\circ}$ ).

A Lei de Biossegurança estabeleceu normas de segurança e mecanismos de fiscalização sobre uma série de processos envolvendo OGMs e seus derivados, além de possuir como diretrizes o estímulo ao avanço científico na área de biossegurança e biotecnologia; a proteção 
à vida e à saúde humana, animal e vegetal; e como já apontado, a observância do princípio da precaução para a proteção do meio ambiente. De acordo com a lei, qualquer OGM deve passar por uma criteriosa avaliação feita pela CTNBio (comissão que reúne especialistas nas áreas vegetal, ambiental, humana e animal, além de representantes dos interesses dos consumidores e de órgão de proteção à saúde do trabalhador). A lei em pauta foi regulamentada pelo Decreto Federal $n^{\circ} 5.591$, de 22 de novembro de 2005.

\section{LEI 13.123/2015 (LEI DA BIODIVERSIDADE) $)^{37}$}

Esta lei regulamenta o inciso II do $\S 1^{\circ}$ e o $\S 4^{\circ}$ do art. 225 da Constituição Federal, o Artigo 1, a alínea j do Artigo 8, a alínea c do Artigo 10, o Artigo 15 e os $\S \S 3^{\circ}$ e $4^{\circ}$ do Artigo 16 da Convenção sobre Diversidade Biológica, promulgada pelo Decreto $\mathrm{n}^{\circ} 2.519$, de 16 de março de 1998; dispõe sobre o acesso ao patrimônio genético, sobre a proteção e o acesso ao conhecimento tradicional associado e sobre a repartição de benefícios para conservação e uso sustentável da biodiversidade, e por fim, revoga a MP No2.186-16/2001. A referida lei trouxe avanços em relação à MP anterior, mas ainda precisava de ajustes, principalmente no caso de pesquisas sem objetivos comerciais.

\section{RESOLUÇÃO NORMATIVA $N^{\circ} 16 / 2018$ CTNBIO $^{38}$}

O desenvolvimento da Resolução Normativa $\mathrm{N}^{\circ}$ 16, de 15 de janeiro de 2018, pela CTNBio, se deu, à luz da Lei 11.105/2005, para suprir a necessidade de avaliar as Técnicas Inovadoras de Melhoramento de Precisão (TIMP - conjunto de novas metodologias e abordagens que diferem da estratégia de engenharia genética por transgenia) e que resultam na ausência de DNA recombinante no produto final, ou seja, as técnicas que podem gerar variantes contendo versões melhoradas de genes já encontrados dentro da variação normal da espécie. Um exemplo destas é justamente nosso objeto de estudo, a edição de genomas por CRISPR. Aliás, este é o primeiro normativo pátrio a tratar mais diretamente do tema.

Além de regular as técnicas de melhoramento genético atuais, incluindo a edição de genomas, a Resolução Normativa $n^{\circ}$ 16/2018 CTNBio exclui os produtos editados da definição de OGMs da lei 11.105/2005, o que virtualmente poderia tornar mais fácil a liberação destes

37 BRASIL. LEI N ${ }^{o} 13.123$ /2015. Dispõe sobre a conservação e uso sustentável da biodiversidade. 2015.

38 CTNBIO. RESOLUÇÃO NORMATIVA Nº 16/2018. Estabelece os requisitos técnicos para apresentação de consulta à CTNBio sobre as Técnicas Inovadoras de Melhoramento de Precisão. 2018. 
no ambiente. Dessa maneira, seria bastante plausível de se imaginar que a edição desta resolução tenha sido influenciada por setores do agronegócio, já que o melhoramento de plantações por CRISPR já é uma realidade mundo afora, aumentando a resistência e o rendimento das colheitas.

\section{PDC 889/2018 (PROJETO DE DECRETO LEGISLATIVO DE SUSTAÇÃO DE ATOS NORMATIVOS DO PODER EXECUTIVO)}

O PDC em tela encontra-se em tramitação na Câmara dos Deputados, e pretende sustar o Artigo $1^{\circ}$ e seu anexo bem como o $\S 4^{\circ}$ do artigo $2^{\circ}$ da Resolução $N^{\circ} 16 / 2018$.

Na prática, este PDC está fundado no princípio da precaução e no da supremacia do interesse público, uma vez que os autores entendem que a relativa facilitação da liberação dos produtos obtidos pelas TIMPs, como aqueles obtidos pela edição de genomas com CRISPR, pode representar riscos que estariam sendo subestimados com a vigência dos dispositivos impugnados da Resolução No 16/2018.

\section{QUESTÕES ÉTICAS NA EDIÇÃO DE GENOMAS: CASOS INTERNACIONAIS}

Embora a edição de genomas pela técnica de CRISPR tenha aplicação em uma série de áreas e organismos, nada tem sido mais polêmico que sua aplicação na edição do genoma de embriões humanos. Como já mencionado anteriormente, em 2018, o mundo assistiu aterrado ao anúncio do nascimento das gêmeas chinesas Lulu e Nana, resistentes ao HIV por deleção do receptor celular CCR5, responsável pela entrada do HIV nas células alvo ${ }^{39}$.

Entre algumas das muitas polêmicas levantadas pelo anúncio do cientista chinês responsável pelo feito estão as seguintes:

- Já era sabido em 2018, em trabalho anterior ao nascimento das gêmeas, que a deleção do gene CCR5, além de impedir a entrada do HIV na células, aparentemente melhorava propriedades cognitivas de camundongos ${ }^{40}$;

39 CYRANOSKI, David; LEDFORD, Heidi. Genome-edited baby claim provokes international outcry. Nature, v. 563, n. 7733, p. 607-608, 2018.

40 ZHOU, Miou et al. CCR5 is a suppressor for cortical plasticity and hippocampal learning and memory. Elife, v. 5, p. e20985, 2016. 
- No entanto, um outro trabalho, divulgado em 2019, posterior ao nascimento das gêmeas, mostrou que havia cerca de $21 \%$ a mais de risco de morte prematura de indivíduos com a mesma mutação $0^{41}$

- Não era exatamente uma necessidade esta abordagem na prevenção do HIV, pois estas gêmeas eram embriões saudáveis e haviam trabalhos em andamento muito mais éticos no sentido de curar a doença em quem realmente já a tem, incluindo o uso de CRISPR de maneira ética ${ }^{42}$

Portanto, diante disso, o que se pergunta é: qual era o real objetivo dos chineses ao manipular os embriões do estudo? De qualquer maneira seria um melhoramento genético, seja tornando-os previamente imunes à infecção por HIV ou, pior do que isso, tencionando tornalos seres humanos com melhor desempenho cognitivo (e numa ou noutra direção, a possibilidade de eugenia aqui é evidente). Além disso, tanto no sentido do melhoramento cognitivo quanto no da probabilidade aumentada de morte, fica evidente a profundidade dos questionamentos e das pesquisas que devem ser feitas previamente à utilização de CRISPR na edição de embriões humanos. Portanto, a colocação de um freio nas pesquisas que utilizam indiscriminadamente a CRISPR em linhagens germinativas sem maiores questionamentos éticos passou de mera preocupação a uma necessidade real ${ }^{43}$

Quanto ao pesquisador chinês líder do estudo que recebeu tantas críticas, este foi afastado de suas funções, e a China acabou por emitir uma normatização pouco mais assertiva para CRISPR em células germinativas (não que já não existisse qualquer normatização). ${ }^{44}$

A reação global mais expressiva ao ocorrido foi o fato de que, no início de 2019, cientistas acabaram por convocar uma moratória internacional em edição de genomas de linhagens germinativas $^{41}$. Nessa convocação, as maiores autoridades científicas da área chamam ao aprofundamento da discussão ética e moral na edição de genomas, sob diferentes perspectivas, considerando inclusive as famílias diretamente interessadas que pesquisas com CRISPR sejam feitas (como por exemplo famílias com a doença genética degenerativa de Huntington, para a qual o CRISPR é uma esperança de erradicação da doença na prole). Além disso, é pedido um maior controle internacional de propostas de estudos de edição genômica, com os esforços

41 WEI, Xinzhu; NIELSEN, Rasmus. CCR5- $\Delta 32$ is deleterious in the homozygous state in humans. Nature medicine, p. 1, 2019

42 DASH, Prasanta K. et al. Sequential LASER ART and CRISPR Treatments Eliminate HIV-1 in a Subset of Infected Humanized Mice. Nature Communications, v. 10, n. 1, p. 2753, 2019.

43 LANDER, Eric S. et al. Adopt a moratorium on heritable genome editing. Nature, v. 567, p. 165-168, 2019.

44 CYRANOSKI, David. China to tighten rules on gene editing in humans. Nature News, 06 March, 2019. 
globais devendo ser direcionados a desenvolver e integrar estratégias legais para prevenção e penalização de pesquisa inaceitável.

No entanto, mesmo assim, propostas de estudos altamente discutíveis utilizando a Edição de Genomas pela técnica CRISPR têm vindo a público, como por exemplo, o anúncio recente de um biólogo russo que planeja mais bebês humanos editados por CRISPR, focando no mesmo gene alterado pelo cientista chinês. ${ }^{45}$ Pesquisadores que participam de um comitê da Organização Mundial da Saúde que está atualmente formulando políticas de governança ética para a edição do genoma humano criticam tal iniciativa e afirmam ser irresponsável prosseguir com este protocolo neste momento.

\section{CONSIDERAÇÕES FINAIS}

Novos avanços na edição de genomas, em termos de aplicações, métodos e utilidade, não param de surgir, impulsionando o arcabouço jurídico a tentar acompanhar esse ritmo, por enquanto, totalmente sem sucesso. A legislação internacional e a brasileira têm ambas ainda muitas lacunas, imprecisões e polêmicas no tema.

Este estudo apenas objetivou fornecer um panorama geral inicial do estado da regulação da matéria, possibilitando como desdobramentos futuros um maior aprofundamento e a elaboração de proposições éticas e normativas passíveis de aproveitamento pelos entes competentes.

\section{REFERÊNCIAS}

ASSEMBLY, UN General. Universal declaration of human rights, 10 December 1948, 217 A (III). 1948.

BARRANGOU, Rodolphe; DOUDNA, Jennifer A. Applications of CRISPR technologies in research and beyond. Nature biotechnology, v. 34, n. 9, p. 933, 2016.

BOBBIO, Norberto. Era dos direitos. Elsevier Brasil, 2004.

BONAVIDES, Paulo. Curso de Direito Constitucional. 26a . São Paulo: Malheiros, 2011.

BRASIL. LEI No 6.938/1981. Dispõe sobre a Política Nacional do Meio Ambiente. 1981.

BRASIL. Constituição da República Federativa do Brasil, promulgada em 05 de outubro de 1988. Brasília, DF: Senado Federal, 1988.

BRASIL. LEI 8974/1995. Dispõe sobre as normas para o uso das técnicas de engenharia genética e liberação no meio ambiente de organismos geneticamente modificados. 1995.

45 CYRANOSKI, D. Russian biologist plans more CRISPR-edited babies. Nature, v. 570, n. 7760, p. 145, 2019. 
BRASIL. MEDIDA PROVISÓRIA №2.186-16/2001. Dispõe sobre dispõe sobre o acesso ao patrimônio genético. 2001.

BRASIL. LEI 11.105/2005. Dispõe sobre as normas de segurança e mecanismos de fiscalização de atividades que envolvam organismos geneticamente modificados. 2005.

BRASIL. LEI $N^{\circ} 13.123$ /2015. Dispõe sobre a conservação e uso sustentável da biodiversidade. 2015.

CALLAWAY, Ewen. UK scientists gain licence to edit genes in human embryos. Nature News, v. 530, n. 7588, p. 18, 2016.

CODE, Nuremberg. The Nuremberg Code. Trials of war criminals before the Nuremberg military tribunals under control council law, v. 10, p. 181-182, 1949.

COUNCIL, OF EUROPE. Convention for the Protection of Human Rights and Dignity of the Human Being with regard to the Application of Biology and Medicine: Convention on Human Rights and Biomedicine. Oviedo: COE, 1997.

CTNBIO. RESOLUÇÃO NORMATIVA Nº 16/2018. Estabelece os requisitos técnicos para apresentação de consulta à CTNBio sobre as Técnicas Inovadoras de Melhoramento de Precisão. 2018.

CYRANOSKI, D. Russian biologist plans more CRISPR-edited babies. Nature, v. 570, n. 7760, p. 145, 2019.

CYRANOSKI, David. China to tighten rules on gene editing in humans. Nature News, 06 March, 2019.

CYRANOSKI, David; LEDFORD, Heidi. Genome-edited baby claim provokes international outcry. Nature, v. 563, n. 7733, p. 607-608, 2018.

DASH, Prasanta K. et al. Sequential LASER ART and CRISPR Treatments Eliminate HIV-1 in a Subset of Infected Humanized Mice. Nature Communications, v. 10, n. 1, p. 2753, 2019.

DECLARAÇÃO Universal sobre o Genoma Humano e os Direitos Humanos. [S.l.: s.n.], 1997. Disponível em: http://unesdoc.unesco.org/images/0012/001229/122990por.pdf. Acesso em: 05 jul. 2019.

DIEDRICH, Gislayne Fátima. Genoma Humano: direito internacional e legislação brasileira. Biodireito, ciência da vida, os novos desafios.(org.) Maria Celeste Cordeiro Leite Santos-São Paulo: RT, 2001.

EUROPEA, Unión. Tratado de Lisboa. Diario Oficial de la Unión Europea, v. 100, 2007.

GATTACA. In: WIKIPÉDIA, a enciclopédia livre. Flórida: Wikimedia Foundation, 2019. Disponível em: <https://pt. wikipedia.org/w/index.php?title=Gattaca\&oldid=55600624>. Acesso em: 28 jun. 2019.

GREEN, Eric D.; WATSON, James D.; COLLINS, Francis S. Human Genome Project: Twenty-five years of big biology. Nature News, v. 526, n. 7571, p. 29, 2015.

HWANG, Woong Y. et al. Efficient genome editing in zebrafish using a CRISPR-Cas system. Nature biotechnology, v. 31, n. 3, p. 227, 2013.

JINEK, Martin et al. A programmable dual-RNA-guided DNA endonuclease in adaptive bacterial immunity. Science, v. 337, n. 6096, p. 816-821, 2012. 
KEVLES, Daniel J.; HOOD, Leroy E. (Ed.). The code of codes: Scientific and social issues in the human genome project. Harvard University Press, 1992.

KOPLIN, Julian J.; GYNGELL, Christopher; SAVULESCU, Julian. Germline gene editing and the precautionary principle. Bioethics, 2019.

LANDER, Eric S. et al. Adopt a moratorium on heritable genome editing. Nature, v. 567, p. 165-168, 2019.

MIRANDA, Jorge; MEDEIROS, Rui; FERREIRA, Eduardo Paz. Constituição portuguesa anotada. Coimbra: Coimbra Editora, 2005.

PARLIAMENTARY Assembly of the Council of Europe. On the use of human embryos and foetuses for diagnostic, therapeutic, scientific, industrial and commercial purposes. Recommendations 1046 and 1100. Strasbourg: Council of Europe, 1986.

RICROCH, Agnès. Global developments of genome editing in agriculture. In: Transgenic research. Springer International Publishing, 2019. p. 45-52

ROCHA, Renata da. Fundamentos do Biodireito. 1. ed. São Paulo: Juspodivm, 2018.

ROCHA, Renata da. $\mathrm{O}$ direito à vida e a pesquisa com células tronco: limites éticos e jurídicos. Rio de Janeiro: Campus jurídicos, 2008.

SANTOS, Maria Celeste Cordeiro Leite et al. Biodireito: ciência da vida, os novos desafios. São Paulo: Revista dos Tribunais, p. 214-245, 2001.

SILVEIRA, Canotilho et al. Carta dos Direitos Fundamentais da União Europeia Comentada. Leya, 2014.

SWISS CONFEDERATION. Federal Constitution of the Swiss Confederation. Disponível em: https://www.admin.ch/opc/en/classified-compilation/19995395/index.html. Acesso em: 25 ago. 2019.

THOMSON, Elizabeth J.; BOYER, Joy T.; MESLIN, Eric Mark. The ethical, legal, and social implications research program at the National Human Genome Research Institute. Kennedy Institute of Ethics Journal, v. 7, n. 3, p. 291-298, 1997.

UNESCO INTERNATIONAL BIOETHICS COMMITTEE et al. Universal declaration on the human genome and human rights. 1997.

VOGEL, Kathleen M. Crispr goes global: a snapshot of rules, policies, and attitudes. Bull At Sci, 2018.

WEI, Xinzhu; NIELSEN, Rasmus. CCR5- $\Delta 32$ is deleterious in the homozygous state in humans. Nature medicine, p. 1, 2019.

ZHOU, Miou et al. CCR5 is a suppressor for cortical plasticity and hippocampal learning and memory. Elife, v. 5, p. e20985, 2016. 